\title{
Do patients with a history of systemic embolism have better compliance in international normalized ratio control?
}

\author{
Anna Tomaszuk-Kazberuk ${ }^{1, \mathrm{~A}, \mathrm{D}, \mathrm{F}}$, Paulina Łopatowska ${ }^{2, A-D}$, Elżbieta Młodawska ${ }^{2, A-D}$, Aleksandra Polak ${ }^{3, B}$, \\ Justyna Sienkiewicz ${ }^{3, B}$, Mateusz Puchalski ${ }^{3, B}$, Ines Kostecka-Rośleńt, ${ }^{4, B}$, Bożena Sobkowicz ${ }^{1, F}$ \\ A - Research concept and design, B - Collection and/or assembly of data, C - Data analysis and interpretation, \\ D - Writing the article, E - Critical revision of the article, F - Final approval of article \\ 1 Department of Cardiology, Medical University in Bialystok, Bialystok, Poland \\ 2 Department of Cardiology, University Hospital in Bialystok, Bialystok, Poland \\ 3 Student Science Club at the Department of Cardiology, Medical University of Bialystok, Bialystok, Poland \\ 4 Department of Haematological Diagnostics, Medical University in Bialystok, Bialystok, Poland
}

Address for correspondence:

Anna Tomaszuk-Kazberuk, Department of Cardiology, Medical University in Bialystok, Bialystok, Poland email: a.tomaszuk@poczta.fm

Paulina Łopatowska, Department of Cardiology, University Hospital in Bialystok, Bialystok, Poland email: plopatowska@gmail.com

Elżbieta Młodawska, Department of Cardiology, University Hospital in Bialystok, Bialystok, Poland email: mlodawska.ela@gmail.com

Aleksandra Polak, Student Science Club at the Department of Cardiology, Medical University of Bialystok, Bialystok, Poland email: alexandra_1991@op.pl

Justyna Sienkiewicz, Student Science Club at the Department of Cardiology, Medical University of Bialystok, Bialystok, Poland email: czuczitka@wp.pl

Mateusz Puchalski

email: puchalskimateusz.pm@gmail.com

Student Science Club at the Department of Cardiology, Medical University of Bialystok, Bialystok, Poland

Ines Kostecka-Rośleń, Department of Haematological Diagnostics, Medical University in Bialystok, Bialystok, Poland email: ineskostecka@interia.pl

Bożena Sobkowicz, Department of Cardiology, Medical University in Bialystok, Bialystok, Poland email: sobkowic@wp.pl

Received: 2018-12-02

Revised: 2019-06-13

Accepted: 2019-06-17

Final review: 2019-06-17

DOI:

\section{Key words:}

\section{What's new?}

Among patients with AF chronic anticoagulant therapy with vitamin $\mathrm{K}$ antagonists (VKA) is suboptimal. Unfortunately, history of thromboembolic events did not cause better international normalized ratio (INR) control. Patients with a history of systemic embolism and very high risk for thromboembolic complications more often had INR below the therapeutic range than the rest of the patients with AF. It can be partly explained by the fact that patients with very high thromboembolic risk at the same time usually have a high risk of bleeding. We may assume that patients with multiple factors associated with inadequate INR may not be ideal candidates for VKA therapy. These patients should be possibly considered for non-vitamin K antagonist oral anticoagulants (NOACs). Further efforts should be made in Poland to improve the quality of antithrombotic care in patients with AF treated with VKA. 


\section{Abstract}

Background: Vitamin K antagonists (VKA) remain viable oral anticoagulants (OAC) for many patients because of their availability and cost.

Aim: The aim of the study was to assess the quality of VKA control in patients with atrial fibrillation admitted to the hospital and the influence of quality of VKA control on in-hospital mortality.

Methods: We retrospectively studied 907 patients with atrial fibrillation (AF). The INR was calculated as the prothrombin time ratio, which uses the International Sensitivity Index (ISI) for an exponent. We recorded one single measurement of INR on admission.

Results: A total of 422 patients with AF on VKA ( 245 male, $59 \%$; mean age $71 \pm 10$ years) were included in the analysis. Of the total international normalized ratio (INR) values, 33\% were in the therapeutic range of $2.0-3.0,46 \%$ were below,

\section{Introduction}

Atrial fibrillation (AF) is the most common sustained cardiac arrhythmia and remains one of the major causes of stroke, systemic embolism, cardiovascular morbidity and mortality in the world ${ }^{[1]}$. This arrhythmia occurs in approximately $3 \%$ of the general population ${ }^{[2,3]}$, with greater prevalence in the elderly and in patients with cardiovascular risk factors such as hypertension, heart failure, coronary artery disease, valvular heart disease, obesity, diabetes and chronic kidney disease ${ }^{[4-11]}$.

Oral anticoagulation $(\mathrm{OAC})$ is an effective therapy recommended for the prevention of thromboembolic complications such as ischemic stroke or systemic embolism in high-risk patients with $\mathrm{AF}{ }^{[1]}$. Treatment with warfarin reduces allcause mortality by $26 \%$ and the rate of stroke by $64 \%$ in this population ${ }^{[12-15]}$. Although non-vitamin $\mathrm{K}$ antagonist oral anticoagulants (NOACs - dabigatran, rivaroxaban, apixaban, edoxaban) are available, vitamin K antagonists (VKA - warfarin, acenocoumarol) remain a viable OAC for many patients because of their availability and cost ${ }^{[16,17]}$.

The therapeutic range for VKA therapy is defined in terms of the international normalized ratio (INR) ${ }^{[18,19]}$.

Nevertheless, data coming from studies such as the GARFIELD-AF registry suggest that a large proportion of patients with AF have poor VKA control and these patients have higher risk of stroke or systemic embolism, major bleeding and allcause mortality ${ }^{[20]}$. Patients after ischemic stroke are in a kind of vicious circle which indicates the high risk of recurrent stroke. Fifty percent of patients after ischemic stroke have another such event within the next five years ${ }^{[21,22]}$.

The aim of the study was general assessment of the quality of VKA control according to single measurement of INR on admission to the hospital in patients with $\mathrm{AF}$ according to the history of thromboembolic events. We also investigated the influence of quality of VKA control on in-hospital all-cause mortality in an AF population. and $21 \%$ were above this range. Patients with INR $<2$ more frequently had a history of systemic embolism ( $6 \%$ vs $2 \%$; $\mathrm{p}=0.04$ ). In the multivariate logistic regression model, odds of INR $<2$ was higher in patients with a history of systemic embolism $(\mathrm{OR}=2.95 ; 95 \% \mathrm{CI}: 1.01-8.59 ; \mathrm{p}=0.05)$. INR control did not differ between patients with and without a history of stroke (29\% vs $33 \%, \mathrm{p}=0.7)$. In patients with $\mathrm{AF}$ and a history of stroke, in-hospital mortality was significantly higher $(8 \%$ vs $2 \%$; $p=0.04$ ).

Conclusions: Among patients with AF chronic anticoagulant therapy with VKA is suboptimal. Unfortunately, history of ischemic stroke did not cause better INR control. Patients with a history of systemic embolism and very high risk for thromboembolic complications more often had INR below the therapeutic range than the rest of the patients with AF.

\section{Methods}

\section{Study population}

We retrospectively studied 907 patients with the diagnosis of AF hospitalized in the Reference Cardiology University Centre in Poland in the years 2016-2017. We excluded patients in whom oral anticoagulation was discontinued before admission to hospital due to planned procedures such as pacemaker implantation, implantable cardioverter-defibrillator implantation, implantation of devices for resynchronization therapy and percutaneous coronary interventions. There were the following reasons for admission to the hospital: paroxysmal symptomatic $\mathrm{AF}$, persistent $\mathrm{AF}$ for electrical cardioversion, ablation of $\mathrm{AF}$, exacerbation of heart failure, exacerbation of coronary artery disease, syncope, syncope with trauma, rhythm disturbances other than $\mathrm{AF}$, uncontrolled hypertension.

Demographic data such as age, sex, medical history and current OAC were determined for all patients. INR was recorded on admission. The study protocol conformed to the ethical guidelines of the 1975 Declaration of Helsinki, and was approved by the local ethics committee. The primary end-point was in-hospital mortality.

INR

The INR is calculated as the prothrombin time ratio (patient prothrombin time/mean of normal prothrombin time for laboratory) ISI, which uses the International Sensitivity Index (ISI) for an exponent, and is dependent on the specific reagents and instruments used in the measurement. We recorded one single measurement of INR on admission, which reflects the general effectiveness of anticoagulation.

\section{Echocardiographic analysis}

Left ventricular ejection fraction (LVEF) was assessed in transthoracic echocardiography using the modified biplane Simpson's method (Philips Ultrasound System EPIQ 7) and was derived in accordance with the recommendations of the European Society of Echocardiography ${ }^{[23]}$. 


\section{Statistical analysis}

Data are expressed as means and standard deviations (SD). Relative frequencies are used to present categorical variables. Student's t test, the Wilcoxon rank-sum test and the chi-square test were used for statistical analysis where applicable. Logistic regression was used to test associations between variables and outcomes. Multinomial logistic regression was used to evaluate the association between variables and in-hospital mortality. A p value of less than 0.05 was considered as statistically significant. The statistical software StataIC (data analysis of statistical software) version 13, was used.

\section{Results}

\section{Baseline characteristics}

A total of 422 patients with AF on VKA (245 male, 59\%; mean age $71 \pm 10$ years) were included in the analysis. Paroxysmal AF was present in $44 \%(n=186)$, persistent in $10 \%(n=$ $42)$, permanent in $46 \%(n=194)$ of the patients. Hypertension was present in $74 \%(n=312)$, diabetes in $27 \%(n=114)$, chronic kidney disease (CKD) in 24\% $(n=101)$, ischemic heart disease (IHD) in $46 \%(n=186)$ and chronic heart failure $(\mathrm{CHF})$ in $72 \%$ $(\mathrm{n}=304)$ of the patients. CHA2DS2-VASc score was $5.1 \pm 1.8$ and HAS-BLED score was $3.4 \pm 1.4$. Clinical characteristics of the population are shown in Table 1 .

Table 1. Clinical characteristics of the population and comparison between patients with therapeutic and non-therapeutic INR

\begin{tabular}{|c|c|c|c|c|}
\hline & $\begin{array}{l}\text { All } \\
\text { patients } \\
(n=422)\end{array}$ & $\begin{array}{l}\text { Thera- } \\
\text { peutic } \\
\text { INR } \\
\text { (n=139) }\end{array}$ & $\begin{array}{l}\text { Non-ther- } \\
\text { apeutic } \\
\text { INR } \\
\text { (n=283) }\end{array}$ & $p$-value \\
\hline Females (\%) & 41 & 38 & 43 & 0.27 \\
\hline Age (years) & $71 \pm 10$ & $70 \pm 10$ & $71 \pm 10$ & 0.32 \\
\hline $\begin{array}{l}\text { CHA2DS2-VASC } \\
\text { score * }\end{array}$ & $5.12 \pm 1.8$ & $4.9 \pm 1.7$ & $5.2 \pm 1.7$ & 0.1 \\
\hline \multicolumn{5}{|l|}{ Type of AF } \\
\hline Paroxysmal (\%) & 43 & 48 & 41 & 0.2 \\
\hline Persistent (\%) & 11 & 14 & 9 & 0.12 \\
\hline Permanent (\%) & 46 & 38 & 50 & 0.03 \\
\hline Hypertension (\%) & 74 & 72 & 76 & 0.38 \\
\hline Diabetes mellitus (\%) & 27 & 30 & 26 & 0.43 \\
\hline $\begin{array}{l}\text { Coronary artery } \\
\text { disease }(\%)\end{array}$ & 46 & 48 & 45 & 0.55 \\
\hline $\begin{array}{l}\text { Chronic heart } \\
\text { failure }(\%)\end{array}$ & 72 & 67 & 74 & 0.14 \\
\hline $\begin{array}{l}\text { Chronic kidney } \\
\text { disease (\%) }\end{array}$ & 24 & 22 & 25 & 0.62 \\
\hline Previous TIA/stroke (\%) & 6 & 5 & 6 & 0.7 \\
\hline $\begin{array}{l}\text { Previous systemic } \\
\text { embolism (\%) }\end{array}$ & 4 & 2 & 5 & 0.18 \\
\hline $\begin{array}{l}\text { In-hospital } \\
\text { mortality (\%) }\end{array}$ & 2 & 2 & 2 & 0.61 \\
\hline
\end{tabular}

Data are presented as mean and standard deviation; AF - atrial fibrillation; TIA - transient ischemic attack

\section{VKA control}

Overall, the mean INR was $2.33 \pm 1.3$. Of the total INR values, $33 \%$ were in the therapeutic range of $2.0-3.0,46 \%$ were below, and 21\% were above this range.

Patients with good INR control less often had permanent type of $\mathrm{AF}$ ( $38 \%$ vs $50 \% ; \mathrm{p}=0.03$ ) (Table 1 ). In the multivariate logistic regression model, odds of the therapeutic range of INR was lower in patients with permanent $\mathrm{AF}(\mathrm{OR}=0.63 ; 95 \% \mathrm{CI}$ : 0.41-0.97; $\mathrm{p}=0.04)($ Table 2$)$.

\begin{tabular}{|c|c|c|c|}
\hline $\begin{array}{l}\text { Odds of therapeutic INR in } \\
\text { AF patients }\end{array}$ & OR & $95 \% \mathrm{Cl}$ & $p$-value \\
\hline $\begin{array}{l}\text { Odds of therapeutic INR in } \\
\text { AF patients }\end{array}$ & OR & $95 \% \mathrm{Cl}$ & $p$-value \\
\hline Age & 0.99 & $0.97-1.02$ & 0.8 \\
\hline Male & 1.25 & $0.81-1.94$ & 0.3 \\
\hline History of stroke & 0.91 & $0.36-2.26$ & 0.83 \\
\hline $\begin{array}{l}\text { History of systemic } \\
\text { embolism }\end{array}$ & 0.45 & $0.12-1.59$ & 0.21 \\
\hline Permanent type of AF & 0.64 & $0.41-0.97$ & 0.04 \\
\hline $\begin{array}{l}\text { Odds of INR }<2 \text { in AF } \\
\text { patients }\end{array}$ & OR & $95 \% \mathrm{Cl}$ & $p$-value \\
\hline Age & 0.99 & $0.97-1.01$ & 0.46 \\
\hline Male & 1.06 & $0.71-1.59$ & 0.77 \\
\hline History of stroke & 2.03 & $0.86-4.80$ & 0.1 \\
\hline $\begin{array}{l}\text { History of systemic } \\
\text { embolism }\end{array}$ & 2.95 & $1.02-8.59$ & 0.04 \\
\hline Permanent type of AF & 1.08 & $0.73-1.61$ & 0.68 \\
\hline
\end{tabular}

AF - atrial fibrillation; OR - odds ratio; CI - confidence interval, INR - international normalized ratio

Patients with INR $<2$ more frequently had a history of systemic embolism ( $6 \%$ vs $2 \%$; $p=0.04)$ and had been treated with warfarin $(39 \%$ vs $27 \% ; p=0.01)$. There were no differences in mortality $(p=0.8)$, CHA2DS2-VASc score $(p=0.7)$ or type of $\mathrm{AF}(\mathrm{p}=0.7)$. In the multivariate logistic regression model, odds of INR $<2$ was higher in patients with a history of systemic embolism (OR $=2.95 ; 95 \%$ CI: 1.01-8.59; $\mathrm{p}=0.05)$ (Table 2).

Patients who received acenocoumarol more often had DM ( $31 \%$ vs $20 \%$; $p=0.01)$, IHD ( $50 \%$ vs $38 \%$; $p=0.02)$ and the therapeutic range of INR ( $58 \%$ vs $45 \%$; $p=0.01$ ) as compared to warfarin.

\section{Male vs female}

Female patients were significantly older $(73 \pm 9$ vs $69 \pm 10$ years; $\mathrm{p}<0.001)$, more often had hypertension $(81 \%$ vs $70 \%$; $\mathrm{p}=0.01)$, a history of stroke ( $9 \% \mathrm{vs} 4 \% ; \mathrm{p}=0.03)$ and had a higher CHA2DS2-VASc score ( $5.9 \pm 1.7$ vs $4.5 \pm 1.6$; $p<0.0001$ ) as compared to males. The value of INR control was similar between men and women $(p=0.2)$.

\section{Patients with thromboembolic events}

Ten percent of the patients had experienced thromboembolic events in the past. History of stroke was present in 6\% (n 
$=25)$ of the patients and history of systemic embolism in $4 \%$ $(n=16)$. Patients with AF and a history of stroke were more frequently male $(p=0.03)$ and had a higher CHA2DS2-VASc score $(6.3 \pm 2.1$ vs $5.0 \pm 1.1 ; p<0.001)$. In this population in-hospital mortality was significantly higher $(8 \%$ vs $2 \%$; $p=0.04)$. INR control did not differ between patients with and without a history of stroke ( $29 \%$ vs $33 \%, p=0.7)$. The percentage of patients within the therapeutic range on warfarin $(29 \%$ vs $33 \%$, $\mathrm{p}=0.7$ ) and acenocoumarol ( $54 \%$ vs $40 \%, \mathrm{p}=0.2)$ was similar.

\section{In-hospital mortality}

In the study population the in-hospital mortality was $2 \%(n=8)$. The in-hospital mortality was higher in males $(p=0.001)$, patients with higher CHA2DS2-VASc score $(p=0.05)$ and with a history of stroke $(p=0.04)$. In the multivariate logistic regression model, odds of in-hospital death were higher only in males $(\mathrm{OR}=0.09$; 95\% CI: 0.01-0.72; $p=0.024$ ) (Table 3).

Table 3. Odds of in-hospital mortality.

\begin{tabular}{|l|l|l|l|}
\hline & OR & $95 \% \mathrm{Cl}$ & $\mathbf{p}$-value \\
\hline Age & 1.02 & $0.95-1.10$ & 0.47 \\
\hline Male & 0.09 & $0.01-0.73$ & 0.02 \\
\hline History of stroke & 3.11 & $0.59-16.22$ & 0.18 \\
\hline Permanent type of AF & 1.22 & $0.33-4.51$ & 0.76 \\
\hline
\end{tabular}

AF - atrial fibrillation

\section{Discussion}

This study revealed that only $33 \%$ of the patients with AF admitted to the hospital had INR within the therapeutic range, the remaining patients showed inadequate therapeutic control. The only factor which significantly and negatively affected INR values within the therapeutic range was permanent type of AF. Patients with a history of systemic embolism and high risk for thromboembolic complications significantly more often had INR below the therapeutic range. History of ischemic stroke did not cause better INR control.

VKA is still used very frequently all over the world but maintenance of proper anticoagulant therapy is still a crucial problem. A study in which the authors enrolled 138319 patients with AF on warfarin in the national assessment of warfarin therapy in the USA had a mean time in therapeutic range (TTR) about $54 \%$. It improved with time on treatment, increasing from $48 \%$ for patients with less than 6 months of testing to $58 \%$ for those with more than 6 months of INR control. The number of patients assessed per physician practice was positively associated with TTR. Female sex, young age and low income were independently associated with poorer control of anticoagulant treatment with INR ${ }^{[24]}$.

TTR is used in research studies, but rarely in clinical practice. In everyday clinical management we very often assess the latest INR. Individual TTR is calculated according to Rosendaal's linear interpolation method. ${ }^{[25]}$. This method is not ideal because it assumes that changes between consecutive INR measurements are linear over time. The method seems to allow the researcher to allocate a specific INR value to each day for each patient. TTR has crucial significance especially if anticoagulant therapy has just started.
Gurwitz et al. conducted a study that investigated the safety of warfarin therapy in the nursing home setting. The percentages of time in the less than 2, between 2 and 3, and more than 3 INR ranges were $36.5 \%, 49.6 \%$, and $13.9 \%$, respectively ${ }^{[26]}$. The Leiden Thrombophilia Study in patients with recurrent venous thrombotic events presented better INR control with TTR of $84 \%{ }^{[27]}$. A study conducted by Cotte et al. revealed that the percentage of patients with poorly controlled treatment varied from 35\% in the United Kingdom to 56\% in Germany. The stroke rate was $0.5 / 100$ person-years in patients with good control, compared with 1.0/100 in patients with poor control. The incidence of hemorrhage was 1.1 and 1.3 events/100 person-years, respectively. The authors underlined that INR in everyday community care is frequently outside the therapeutic range, and patients are exposed to an unnecessary risk of both stroke and bleeding ${ }^{[28]}$.

The study carried out in Poland by Dereziński et al. analyzed the effectiveness of anticoagulation in primary care. They analyzed 964 INR measurements and found that only $56.84 \%$ of them were within the therapeutic range during the one-year follow-up. Moreover, they found no correlation between the number of INR measurements and effectiveness of treatment. The minority of patients (30\%) had more than $70 \%$ of INR measurements within the limit of the therapeutic range ${ }^{[29]}$.

Similar results were presented by Sawicka-Powierza et al., where the TTR value in 430 patients was $55 \%{ }^{[30]}$. It is noteworthy that in the above-mentioned study male gender was the only obvious and significant independent predictor of INR results above the upper limit of the therapeutic range. In our study INR control was similar among both sexes.

Community-based practice data presented good quality of anticoagulation in patients on warfarin with mean TTR of $66.5 \%{ }^{[31]}$. According to the ORBIT-AF registry only $59 \%$ of all INR values were in the therapeutic range. Warfarin patients followed at special anticoagulation clinics had higher median TTR $(69 \%)$ than those patients not followed at such clinics $(66 \%)^{[32]}$. In this registry patients with poorer control were more often female, nonwhite and had less college education.

Nevertheless, a report from the Swedish quality register Auricula showed that efficient warfarin therapy with a mean TTR of $76.5 \%$ is possible to achieve in routine clinical care with unselected patients. Moreover, the authors claim that warfarin treatment with proper therapeutic values of INR performs well, and should not be ruled out in favor of NOACs although NOACs according both to randomized trials and registries are safer than warfarin, because they cause significantly fewer major bleeding events and especially dramatically reduce the rate of intracranial bleeding ${ }^{[33]}$. Some NOACs even have their specific reversal agents - idarucizumab for dabigatran and andexanet alfa for rivaroxaban - which raises safety of the anticoagulant treatment especially in the case of life-threatening bleeding or emergency settings ${ }^{[34]}$. Although NOACs are nowadays the preferred therapeutic option according to European Society of Cardiology guidelines, patients with markedly reduced renal function, especially with eGFR $<30$ $\mathrm{ml} / \mathrm{min}$, benefit from VKA treatment ${ }^{[35]}$. Also patients after kidney transplantation are limited to use of VKA ${ }^{[36,37,38]}$. From 
the latest trials we know already that NOACs combined with antiplatelet agents cause significantly less bleeding than combination of warfarin and antiplatelet agents ${ }^{[39]}$.

Generally the poor control of anticoagulant treatment with VKA can be partly explained by the fact that patients with very high thromboembolic risk at the same time usually represent high risk of bleeding. We may assume that patients with multiple factors associated with inadequate INR may not be ideal candidates for VKA therapy. These patients should be possibly considered for NOACs. Further efforts should be guaranteed in Poland to improve the quality of antithrombotic care in patients with AF treated with VKA.

What is the way to improve the quality of the anticoagulation therapy apart from strict INR control then? Undas et al. observed that switching acenocoumarol to warfarin in patients with unstable anticoagulation improves the quality of anticoagulation. The factor of transition between acenocoumarol and warfarin was assessed as 1.8. The TTR in patients with poor anticoagulation was $40.2 \%$ at baseline and rose to $60.4 \%$ during 6 months on the treatment with warfarin $(p<0.05)$ [40]. In our study the percentage of patients within the therapeutic range on warfarin and acenocoumarol was similar. However, individuals with INR below 2 on admission were more often treated with warfarin. Type of VKA did not influence the in-hospital mortality.

It is worth noting that in our population with a history of stroke in-hospital mortality was significantly higher ( $8 \%$ vs $2 \% ; \mathrm{p}=0.04)$. Patients with AF and a history of stroke were slightly older, more often had the permanent type of atrial fibrillation, and had a significantly higher CHA2DS2-VASc score $(6.3 \pm 2.1$ vs $5.0 \pm 1.1 ; p<0.001)$, which means that they more often had significant comorbidities such as coronary artery disease, diabetes mellitus, and chronic kidney disease. Although the differences were numerically higher, they did not reach statistical significance. There are very scarce data in the literature on prognosis in patients with a history of stroke during hospitalizations due to other reasons than stroke as compared to the rest of the population with AF.

We believe that these data are of value in the population of patients with $\mathrm{AF}$ treated with vitamin $\mathrm{K}$ antagonist oral anticoagulants. The strength of our study is the inclusion of 'real-world' patients treated with vitamin $\mathrm{K}$ antagonist oral anticoagulants admitted to the hospital for various reasons except for elective procedures.

This study has all the limitations of an observational study as the decision about antithrombotic treatment and the doses of the drugs were entirely at the discretion of the treating physician. We did not have enough data to analyze a long follow-up. Unfortunately data regarding the therapy and the baseline laboratory tests are not available. We would like underline that conclusions regarding outcome data should be evaluated with caution due to the retrospective nature of the study.

In conclusion, among patients with AF chronic anticoagulant therapy with VKA is suboptimal. Unfortunately, a history of ischemic stroke did not cause better INR control. Patients with a history of systemic embolism and very high risk for thromboembolic complications more often had INR below the therapeutic range than the rest of the patients with AF.

\section{References}

1. Kirchhof P, Benussi S, Kotecha D, et al. 2016 ESC Guidelines for the management of atrial fibrillation developed in collaboration with EACTS. Europace. 2016;18:1609-1678.

2. Bjorck S, Pałaszewski B, Friberg L, Bergfeldt L. Atrial fibrillation, stroke risk, and warfarin therapy revisited: a population-based study. Stroke. 2013;44:3103-3108.

3. Haim M, Hoshen M, Reges O, et al. Prospective national study of the prevalence, incidence, management and outcome of a large contemporary cohort of patients with incident non-valvular atrial fibrillation. J Am Heart Assoc. 2015;4:e001486.

4. Zoni-Berisso M, Lercari F, Carazza T, Domenicucci S. Epidemiology of atrial fibrillation: European perspective. Clin Epidemiol. 2014;6:213-220.

5. McManus DD, Rienstra M, Benjamin EJ. An update on the prognosis of patients with atrial fibrillation. Circulation. 2012;126:e143-146.

6. Ball J, Carrington MJ, McMurray JJ, Stewart S. Atrial fibrillation: profile and burden of an evolving epidemic in the 21st century. Int J Cardiol. 2013;167:1807-1824.

7. Kannel WB, Wolf PA, Benjamin EJ, Levy D. Prevalence, incidence, prognosis, and predisposing conditions for atrial fibrillation: population-based estimates. Am J Cardiol. 1998; 82: 2N-9N.

8. Nguyen TN, Hilmer SN, Cumming RG. Review of epidemiology and management of atrial fibrillation in developing countries. Int J Cardiol. 2013;167:2412-2420.

9. Oldgren J, Healey JS, Ezekowitz M, et al.; RE-LY Atrial Fibrillation Registry Investigators. Variations in cause and management of atrial fibrillation in a prospective registry of 15,400 emergency department patients in 46 countries: the RE-LY Atrial Fibrillation Registry. Circulation. 2014; 129:1568-1576.

10. Chiang CE, Naditch-Brule L, Murin J, et al. Distribution and risk profile of paroxysmal, persistent, and permanent atrial fibrillation in routine clinical practice: insight from the reallife global survey evaluating patients with atrial fibrillation international registry. Circ Arrhythm Electrophysiol. 2012; 5:632-639.

11. Ozierański K, Kapłon-Cieślicka A, Peller M, et al., Clinical characteristics and predictors of one-year 
outcome of heart failure patients with atrial fibrillation compared to heart failure patients in sinus rhythm. Kardiol Pol. 2016; 74(3): 251-261.

12. Connolly SJ, Wallentin L, Yusuf S. Additional events in the RE-LY trial. Engl J Med. 2014; 371(15): 1464-1465.

13. Granger CB, Alexander JH, McMurray JJ, et al. Apixaban versus warfarin in patients with atrial fibrillation. N Engl J Med. 2011;365:981-992.

14. Patel MR, Mahaffey KW, Garg J, et al. Rivaroxaban versus warfarin in non-valvular atrial fibrillation. N Engl J Med. 2011; 365:883-891.

15. Giugliano RP, Ruff CT, Braunwald E, et al. Edoxaban versus warfarin in patients with atrial fibrillation. N Engl J Med. 2013; 369: 2093-2104.

16. You JH. Novel oral anticoagulants versus warfarin therapy at various levels of anticoagulation control in atrial fibrillation: A cost-effectiveness analysis. Journal of General Internal Medicine. 2014; 29:438-446.

17. Cozma D, Streian CG, Vacarescu C, Mornos C. Back to sinus rhythm from atrial flutter or fibrillation: dabigatran is safe without transoesophageal control. Kardiol Pol. 2016; 74(5): 425-430.

18. Farsad B-F, Abbasinazari M, Dabagh A, Bakshandeh H. Evaluation of Time in Therapeutic Range (TTR) in patients with non-valvular atrial fibrillation receiving treatment with warfarin in Tehran, Iran: a cross-sectional study. Journal of Clinical and Diagnostic Research: JCDR. 2016;10:FC04-FC06.

19. Ansell J, Hirsh J, Hylek E, et al. Pharmacology and management of the vitamin K antagonists: American College of Chest Physicians Evidence-Based Clinical Practice Guidelines (8th Edition). Chest. 2008; 133:160S-198S.

20. Haas S, Ten Cate H, Accetta G, et al. Quality of vitamin $\mathrm{K}$ antagonist control and 1-year outcomes in patients with atrial fibrillation: a global perspective from the GARFIELD-AF Registry. PLoS One. 2016;11:e0164076

21. Stępińska J, Kremis E, Konopka A, et al. Gloria Kayani Stroke prevention in atrial fibrillation patients in Poland and other European countries: insights from the GARFIELD-AF registry. Kardiol Pol. 2016; 74(4): 362-371.

22. Quan D, Huang H, Kong B, et al. Predictors of late atrial fibrillation recurrence after cryoballoon-based pulmonary vein isolation: a me- ta-analysis Kardiol Pol. 2017; 75(4):376-385.

23. Lang RM, Badano LP, Mor-Avi V, et al. Recommendations for cardiac chamber quantification by echocardiography in adults: an update from the American Society of Echocardiography and the European Association of Cardiovascular Imaging. J Am Soc Echocardiogr. 2015;28:1-39.e14.

24. Dlott JS, George RA, Huang X et al. National assessment of warfarin anticoagulation therapy for stroke prevention in atrial fibrillation. Circulation. 2014;129:1407-1414.

25. Rosendaal FR, Cannegieter SC, van der Meer FJ, BrietE. A method to determine the optimal intensity of oral anticoagulant therapy. Thromb Haemost. 1993;69(3):236-239.

26. Gurwitz JH, Field TS, Radford MJ, et al. The safety of warfarin therapy in the nursing home setting. Am J Med. 2007; 120: 539-544.

27. Gadisseur AP, Christiansen SC, VAN DER Meer FJ, et al. The quality of oral anticoagulant therapy and recurrent venous thrombotic events in the Leiden Thrombophilia Study. J Thromb Haemost. 2007;5:931-936.

28. Cotté FE, Benhaddi H, Duprat-Lomon I, et al. Vitamin $\mathrm{K}$ antagonist treatment in patients with atrial fibrillation and time in therapeutic range in four European countries. Clin Ther. 2014;36:1160-1168.

29. Dereziński T, Wąsikowska B, Strzeboński B, et al. Outpatient oral anticoagulation in Poland in 2012: a single centre experience. Kardiol Pol. 2013; 71:1135-1139.

30. Sawicka-Powierza J, Buczkowski K, Chlabicz S, et al. Quality control of oral anticoagulation with vitamin $\mathrm{K}$ antagonists in primary care patients in Poland: a multi-centre study. Kardiol Pol. 2018;76:764-769.

31. Rose AJ, Ozonoff A, Henault LE, et al. Warfarin for atrial fibrillation in community based practise. J Thromb Haemost. 2008; 6:1647-1654.

32. Pokorney SD, Simon DN, Thomas L, et al. Patients' time in therapeutic range on warfarin among US patients with atrial fibrillation: Results from ORBIT-AF registry. Am Heart J. 2015;170:141-148.

33. Sjögren V, Grzymala-Lubanski B, Renlund H, et al. Safety and efficacy of well managed warfarin. A report from the Swedish quality register Auricula. Thromb Haemost. 2015; 113:1370-1377. 
34. Pruszczyk P, Tomaszuk-Kazberuk A, Słowik A, et al. Management of bleeding or urgent interventions in patients treated with direct oral anticoagulants: 2017 recommendations for Poland. Pol Arch Intern Med. 2017; 127 (5):343-351.

35. Tomaszuk-Kazberuk A, Łopatowska P, Młodawska E, et al. Successful use of idarucizumab as a reversal agent for dabigatran in a patient with acute dissected aortic aneurysm. Pol Arch Intern Med. 2017; 127(1):68-70.

36. Młodawska E, Tomaszuk-Kazberuk A, Łopatowska $\mathrm{P}$, et al. Management of patients with atrial fibrillation and chronic kidney disease in light of the latest guidelines. Pol Arch Med Wewn. 2016;126(5):353-362.

37. Małyszko J, Bachorzewska-Gajewska H, Tomaszuk-Kazberuk A, et al. Cardiovascular disease and kidney transplantation evaluation of potential transplant recipient. Pol Arch Med Wewn. 2014; 124(11): 608-616.

38. Małyszko J, Łopatowska P, Młodawska E, et al. Atrial fibrillation in kidney transplant recipients: is there a place for the novel drugs? Nephrol Dial Transplant. 2018; 33 (8): 1304-1309.

39. Michniewicz E, Młodawska E, Łopatowska P, et al. Patients with atrial fibrillation and coronary artery disease - Double trouble. Adv Med Sci. 2018; 63(1):30-35.

40. Undas A, Cieśla-Dul M, Żółciński M, et al. Switching from acenocoumarol to warfarin in patients with unstable anticoagulation and its effect on anticoagulation control. Pol Arch Med Wewn. 2009;119:360-365. 